\title{
Emerging industry: Identifying the Effective Institutional Factors on the Exploitation of Entrepreneurial Opportunities of Sports Tourism Industry in developing countries
}

\author{
Reza Heydari ${ }^{1}$, Mohammad Keshtidar ${ }^{2 *}$, Haywantee Ramkissoon $^{3}$, Mahdi Esfahani ${ }^{4}$, Ehsan \\ Asadollahi ${ }^{5}$
}

${ }^{1} \mathrm{Ph} . \mathrm{D}$ Student Sport management, Faculty of Sports Sciences,Ferdowsi University of Mashhad, Mashhad, 9177948979, Azadi Square, Iran

${ }^{2}$ Associate Professor of sport management, Faculty of Sports Sciences,Ferdowsi University of Mashhad, Mashhad, 9177948979, Azadi Square, Iran

${ }^{3}$ Research Professor Tourism Marketing , Centre for Contemporary Hospitality \& Tourism, School of Business, Law \& Social Science ,University of Derby ,Kedleston Road ,Derby,United Kingdom

${ }^{4}$ Sports Centre, Imam Reza International University, Iran

${ }^{5}$ Faculty member of Sanabad Golbahar University, Golbahar, Iran

*Correspondence: keshtidar@um.ac.ir

\begin{abstract}
The aim of this study is to identify the effective institutional factors on the exploitation of entrepreneurial opportunities of the sports tourism industry in developing countries. This research is a qualitative study, the systematic method of Strauss and Corbin (1990) has been used to analyze the data. Interviewing is the main method of collecting data in this research, which semi-structured interviews were done with 45 members of the research community. According to Shane and Vankataraman individual-opportunity nexus framework (2000), interview questions were drafted and simultaneously with data collection from interviews, data analysis was performed. Based on the research results, 75 indicators affecting the exploitation of entrepreneurship opportunities in sports tourism were identified. Our research findings show that the necessary institutional arrangements in regulatory/legal/administrative dimensions (rule of law, government policies), normative/cultural (social norms, values and beliefs), cognitive/educational (promotion of elite knowledge, promotion of social knowledge) and guidance measures/supporter (public sector support, private sector support, complementary attraction and information technology) can improve the rate of entrepreneurial behavior in this area by increasing the ability and willingness of entrepreneurs to take advantage of entrepreneurial opportunities in the field of sports tourism. Finally, according to the research results, it can be suggested that for the growth of the sports tourism industry in developing countries, The existence of a legal, normative, supportive and educational environment will affect the ability and desire of market participants to identify and exploit the entrepreneurial opportunities of this emerging industry.
\end{abstract}

Keywords: Tourism industry, sports tourism, entrepreneurship, institutional factors, development. 


\section{Introduction}

The tourism industry is one of the important economic phenomena and resources and a factor in the cultural, social and economic development of human societies [1]. With the development of technology, information technology and transportation, the tourism industry is one of the strongest and largest industries in the world [2,3]. Many developing countries are heavily dependent on tourism for the livelihoods. Economists often label the tourism industry as the invisible economy [4]. According to the forecasts of the World Tourism Organization pre COVID-19 health pandemic, the number of tourists was expected to increase to 1.6 billion in 2020 and to 1.8 billion in 2030 [5]. The World Tourism Council predicted that in 2027 the tourism industry will be expected to support more than 380 million jobs globally and may be ahead of other global sectors of the economy e.g. communications, business and economic services, manufacturing, retail and distribution. Dubreuil's (2009) provided a classification of jobs in tourism (1) jobs not attributed to tourism demand, (2) jobs attributed to tourism demand, (3) jobs in other industries except tourism, which are attributed to the demand for tourism, and (4) all the jobs that can be attributed to the demand for tourism. Also, various types of tourism are highly regarded by employers and entrepreneurs, and each region in a way and according to their existing conditions, and benefits from different types of tourism e.g. historical, cultural, medical and sports among others. The sports tourism industry remains significant [6]with important impacts on the society and economy providing individuals an opportunity for their entrepreneurial activities.

Sport has become one of the most common motivating factors for tourists around the world, and countries have become more inclined to earn more money through new methods and innovations in the industry [7]. Sports and tourism are inextricably linked. Most countries in the world that have natural and cultural heritage sites use sports tourism as a strategic tool in job creation and economic development [8]. Sports tourism beyond an industry is considered as a socio-economic phenomenon in the world and many countries and cities of the world with investment, understand the many benefits and effects of this industry and so that they use it as an important source to improve the economic, social and politic situations, increasing fame and destination branding, and enhancing employment, income, and infrastructure development [9-11]. Trade, sports and tourism are topics that able to be integrated and the resulting combination is so profitable that all countries, regions, cities, travel agencies and sports can benefit from it [12]. That's why economists are focusing on sports tourism; because they believe that sports tourism is a productive industry for job creation and entrepreneurship. With the development of sports tourism activities, the ground is created for job creation, and this is very useful for developing countries such as Iran, which has a young population and job seekers [13]. Iran with its natural potential and tourist and cultural attractions, as well as its diverse climate and four seasons as a capable country in preparing favorable conditions for those interested in foreign travel, can be considered as an important pole in the tourism industry in the general sense and sports tourism in its specific meaning.; However, the sports tourism industry in Iran is an emerging industry and due to the dependence of the Iranian economy on oil incomes and products; less use of these resources and potentials has been made for entrepreneurship, job creation and economic development in the country [14]. The new age is the arena of competition for resources and capital; the great industrialized nations, which are the victors in this field, have made the exploitation of resources and capital their top priority, and in the light of the presence of educated and skilled people, they have initiated cycles of growth and development and achieved innovations and innovations. Access to these innovations, which have revived the economies of developed countries, depends on entrepreneurship [15] 
Entrepreneurship is important because it drives society toward technical and innovative change, economic growth, and the transformation of new knowledge into new products. Today, both in developed and developing countries, the greatest privilege for any industry, organization, and individual is to have a mindset and creativity for entrepreneurship. Despite the many opportunities in the sports tourism sector for developing countries entrepreneurs to create jobs, wealth and value, there is little understanding of the institutional factors influencing the exploitation of entrepreneurial opportunities in the sports tourism industry specially in developing countries. Individual-opportunity nexus framework [16] in entrepreneurship suggests that entrepreneurship is essentially the result of a link between individuals (entrepreneurs and organizations) and the environment or opportunity. Opportunity refers to a set of conditions that make entrepreneurial ideas for new products or services desirable and feasible [17]. This set of environmental factors affects the cost, time, and type of entrepreneurial activity; So that if the set of conditions does not exist in a desirable way, entrepreneurial activities will be done at a higher cost and time, and the type of activities may be from productive to unproductive, formal to informal; Innovative to imitation and opportunity-oriented to be forced [18]. One of the important environmental factors that affect entrepreneurial processes is institutional factors. Institutions are human-defined frameworks that guide their behavior $[19,20]$

These days, employment and entrepreneurship is one of the main concerns of government officials and those involved in employment in countries. They are constantly trying to make up for this shortcoming, and they are pursuing a variety of ways, one of which is to focus on the sports tourism industry. The sports tourism industry is an entrepreneurial and employment-generating one, and overall, one of the most effective ways to overcome the problem of unemployment in countries is to develop this industry. The importance of sports tourism, in addition to economic well-being, is to create jobs in providing its services; most of these services require direct manpower and so whether or not that will create jobs in the region. In view point of the great potentials in the field of sports tourism, it seems that there are many entrepreneurial opportunities in the field of sports tourism in countries, especially Iran, which requires the necessary institutional arrangements to increase the desirability and feasibility of entrepreneurial activities in this area. Previous research has provided little insight into the field and so this research, with a new and innovative approach to entrepreneurship in the sports tourism industry, pays special attention to the environment, opportunities and institutional factors. Certainly, entrepreneurs in the field of sports tourism in different countries, which has a different institutional background, need to accurately identify these factors in order to bring their creative thoughts and ideas closer to practice and start a new business. Therefore, this research seeks to identify the effective institutional factors on the exploitation of entrepreneurial opportunities in the emerging field of sports tourism in developing countries with a qualitative and exploratory approach.

\section{Literature Review}

\section{2-1. Sports Tourism}

Today, tourism is considered as an attractive and growing industry. Tourism is an ancient phenomenon that is based on human movement and movement [21]. Tourism and sports are the largest industry of the world, which by combine of them, one of the most amazing modern service industries has been created, called the sports tourism industry [22]. Sports tourism is one of the types of tourism that plays an important and effective role in achieving tourism goals in any society and in recent years has been a major part of the success of communities in the field of tourism [13]. Sports tourism, as a special type of tourism, faces tourists to extraordinary experiences [23]. 
Sport is one of the most important activities during tourism, and tourism is associated with different types of sports. Watanabe et al. (2018) also stated that sports tourism is one of the significant types of tourism that causes the growth and expansion of tourism in Malaysia[24]. Gibson et al. (2012) in an article examining the sports tourism event in six events over 18 months, discussed the economic variable and they came to the conclusion that the presence of spectators in the venue leads to the financial well-being of individuals and the jobs creation and the injection of money into that society[13]. Hinch and Ito (2018) announced that sports tourism and exploiting its potential is one of the important goals of Japan in some upcoming sporting events, including the 2019 Rugby World Cup in Japan and the 2020 Tokyo Olympics[25]. Research by Hodeck et al. (2018) also showed that sports tourism played an important role in the success and achievement of the goals of the Rio 2016 Olympics. In a study titled "Structural Analysis of Physical Education and Sports System in the Republic of Northern Cyprus", Deniz and Yenel (2013) stated that sports associations and the Ministry of Tourism should create a joint group to improve sports tourism using the country's natural resources[26, 27]. According to the World Tourism Organization and tourism forecasts by 2030, the number of tourists entering emerging destinations is expected to double between 2010 and 2030 [5]. The tourism industry in developing countries has a very high capacity for growth and development. Meanwhile, the tourism industry in developing countries, as it should be, has not grown and developed; this emerging industry is of particular importance to developing countries such as Iran, which face to problems including high unemployment, limited foreign exchange reserves, and a single-product economy based on oil and oil products.

\section{2-2. Entrepreneurship in sports tourism}

Forecasts show that tourism and travel will grow by $5 \%$ worldwide by 2020 , but it is interesting to note that these predictions for sports tourism by the end of 2020 show a figure of $10 \%$. The Secretary-General of the World Tourism Organization and the President of the International Olympic Committee stressed in a joint message that tourism and sports are two driving forces for stability in economic growth, job creation and income growth (World Tourism Organization). When sports spectators and foreign tourists buy goods and services in the host country, the income from foreign exchange is injected into the domestic economy, which makes the domestic business more profitable, increases the tax rate and creates new Job opportunities [28]. Nova (2015) also introduces the sports tourism industry as one of the priorities in examining entrepreneurial opportunities in sports management students[29]. In addition, Ball (2005) in examining the importance of entrepreneurship in leisure, sports and tourism, stated that entrepreneurship is a key factor in the prosperity of businesses related to these three areas[30]. Entrepreneurship in sports tourism can be the production of a product or the provision of new services that usable in the field of sports to start a sports business [31]. Entrepreneurship in the sports tourism industry with a significant role in the development of business, employment, welfare and mental and physical health can be very effective in the development of countries. Entrepreneurship is very important for tourism success; However, it is surprising that such limited attention has been paid to entrepreneurship in sports tourism in the main journals related to entrepreneurship, which shows the lack of participation of academics in sports tourism and the lack of experts and professors of entrepreneurship who consider to sports tourism that indicate this field is an interesting and new one of research [32]. Entrepreneurship emphasizes opportunities to create and manage jobs and organizations. In addition, entrepreneurship has a significant impact on the development of tourism destinations. Entrepreneurs think of a creative idea or see an opportunity and pursue it, and as a result, they start a business. Such behavior explains the impact of entrepreneurs on tourism 
destination development [33]. Sports entrepreneurship is a fast-growing field of research in which sports management is combined with innovation and entrepreneurial research. What distinguishes entrepreneurial activities from near-field research is the focus on the process of business emergence or new socio-economic activity [17, 31]. This phenomenon has economic, social, environmental and individual effects at different levels of analysis [34]. In other words, entrepreneurship is a great tool for promoting economic growth and job creation in societies [35], especially in the sports tourism industry as a highly competitive one that plays a role in the economic development of any region, because the industry includes catering, sightseeing, transportation, shopping, adventure and other aspects [36]. There are many resources and capacities for the development of entrepreneurship in sports tourism, which have been neglected in terms of performance and research. Also, the turnover in some areas of sports services or sports tourism in developing countriesis such that the expansion of related activities and creating a platform for people to enter this field can lead to the creation of one of the largest entrepreneurship poles in sports. Due to the fact that the desired environment increases the rate of entrepreneurial behavior, since the 1990s, most entrepreneurial attention has been focused on the environment [37]. Towards the end of this decade, the article of Shane and Venkataraman (2000), selected as the best entrepreneurship decade one in 2010, proposed individual-opportunity nexus framework and suggested that entrepreneurship is a combination of opportunity as a set of conditions that makes entrepreneurial behavior desirable and possible, and the agent as an individual or a company that engages in entrepreneurial behavior[16]. Therefore, this paper suggests that each of the two factors of individual and opportunity or environment alone cannot form an entrepreneurial output and as important as "individuals", "environment" and opportunity also play a role in creating and improving the quality of entrepreneurial activity. Accordingly, the environment and the set of conditions that help an entrepreneur realize his or her idea of exploiting entrepreneurial opportunities are important; So that the unfavorable background of the entrepreneur leads to lack of exploitation or low quality entrepreneurial behaviors [18]. One of these environmental factors is "institutions" that play an irreplaceable role in the desirability and feasibility of entrepreneurial behaviors and ideas [19].

\section{2-3. Institutional factors}

For the development of entrepreneurship in sports tourism, what is of special importance is to pay attention to the factors that can affect it. So that identify and examine the various institutional factors affecting entrepreneurship in sports tourism can play an effective role in macro-planning and policy-making to promote entrepreneurial activities. Institutions are the rules of the game in a society, or more formally, the rules and principles that shape the interaction of human beings and human societies, and individuals or organizations, as actors, shape their behavior within an institutional framework. The institutional perspective argues that in addition to the conditions and characteristics of organizations and the structure of industry, organizations need to consider the effects of other factors such as rules and regulations and the culture of societies on their managerial choices and activities $[19,38]$. Non-business institutional factors can affect the organization and cause the success or failure of the business and have significant effects on the performance of a business in various fields such as its export performance [39, 40]. Institutions can formally determine the culture of a society, such as political and economic laws, laws, treaties, or informally, including behavior, attitudes, values, and behavioral norms and in general designate the culture of a society. According to North's (1990) theory, formal institutions are dependent on informal institutions, in the sense that they use the structure of society's interactions in line with 
the values and cultural guidelines of formal institutions as predicted form. Formal institutional factors are the ones that are formally formulated and are the system of enforced implementation of laws in an association and society and include regulatory institutions such as economic and political laws [41]. Scott (1995) also places institutions in three legal, normative, and cognitive categories [42], which provide the necessary incentives to guide or prevent social behavior such as entrepreneurial activity in an economy. The legal dimension of the environment relates to regulations, policies, rules, and laws that affect the entrepreneurial behavior of individuals and the rate of entrepreneurship; Because better laws lead to reduction of entry barriers and more business opportunities. The normative dimension of the environment includes social norms, values, and beliefs related to the entrepreneurial behavior of individuals in society. The cognitive dimension of the environment includes the cognitive frameworks and social knowledge that individuals share in a society, through which they select and interpret information [43, 44]. Stenholm et al. (2013) added another dimension called the environmental guide dimension to the three normative, legal, and cognitive dimensions of Scott (1995). The guide dimension of a set of fertile conditions and industries includes access to customers and suppliers and proximity to top universities, which affects the type of opportunities used in a system and provides the necessary ground for productive, innovative and high-growth entrepreneurship [43]. Kana et al. (2013) argue that the main function of institutions is to reduce uncertainty and the cost of exchanges. The uncertainty and cost of trading in a system is reduced in two ways; First, through the personal and non-interference of third parties / institutions providing information, and second, through market institutions. In fact, by reducing the cost and time of access to quality inputs (human, financial, and commodity), preexchange assessment, and achieving property rights after the exchange, institutions can reduce market transaction costs. Institutions significantly reduce costs in the exchange process as well as increase efficiency in the economy, and by creating a stable structure for interaction, reduce market uncertainty and increase market competition. Countries with better institutions and countries with more entrepreneurial and commercial businesses are more likely to grow economically [45, 46]. In a study titled The Impact of Official Institutions on the Performance of the Tourism Sector in the Philippines by Considering the Mediation of Entrepreneurship, Kaynak \& Kuan (1993) considered institutional factors including rule of law, quality regulation, government policies, and business support. The impact of these components on the performance of the tourism sector in the Philippines was examined[47]. The results showed that the elements of the institutional environment have a limited impact on the performance of tourism businesses. According to Rodrick et al. (2004), entrepreneurship emphasizes the role of institutions in the performance of businesses and considers it to be measurable over time due to institutional developments that are not measurable and reflects the existence of contracts in economic, social, cultural and political relations between individuals and societies[48].

\section{Hypotheses and theoretical framework of research}

Research literature and theoretical foundations show that the exploitation of opportunities (such as sports tourism) requires the existence of institutions that increase the ability and willingness of individuals (entrepreneurs) to exploit these opportunities. Previous research has provided little insight into institutional factors in the field of sports tourism in developing countries' institutional and cultural context. Undoubtedly, the exploitation of sports tourism opportunities in developing countries requires market institutions to reduce the cost and time of entrepreneurial behaviors to take advantage of these opportunities. Therefore, this research seeks to identify the institutional factors affecting the exploitation of entrepreneurial opportunities in the field of sports tourism with 
a special focus on developing countries with a qualitative and exploratory approach. Accordingly, according to the theoretical foundations and research literature, in the present study, the institutional environment in four regulatory / legal / administrative, normative / cultural and cognitive / educational dimensions [42] and guiding / supporting [43] are noted that the research propositions can be extracted as follows:

1. The regulatory / legal / administrative dimension influences adoption of sports tourism entrepreneurship opportunities.

2. The normative / cultural dimension influences adoption of sports tourism entrepreneurship opportunities.

3. The cognitive / educational dimension influences adoption of sports tourism entrepreneurship opportunities.

4. The guiding / supportive dimension influences adoption of sports tourism entrepreneurship opportunities.

The theoretical framework of the research is presented in Figure 1.
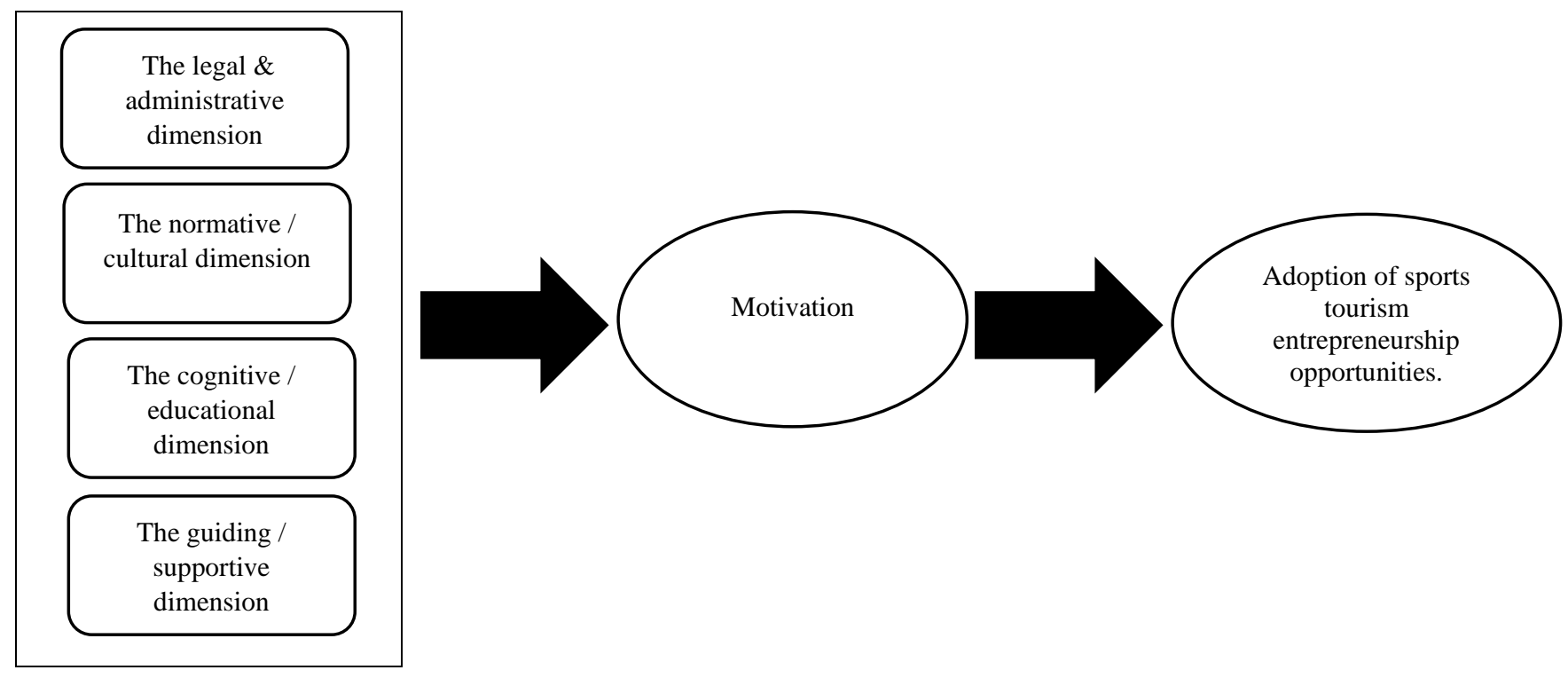

\section{Methodology}

Figure 1: Initial research framework

The present study is an applied research in terms of purpose. The research approach is qualitative, which has been done with the method of data foundation theory; Because the nature of research is exploratory, the researcher seeks to gather data from the field to answer the research questions, and there is no initial hypothesis (s) for the test, calculated from the literature [17]. It is often used in the social sciences and tourism [49], when the Foundation's data theorizing is used when a theory or general explanation of a process is needed. This theory provides a better explanation of the subject and fits the situation. The method of data foundation theory is usually implemented in three ways: systematic, new and adaptive. In this research, a systematic method attributed to Strauss and Corbin has been used to analyze the data. The reason for using this method is to evaluate the different aspects of the research subject that this method includes. Thematic and spatial domain of identifying institutional factors affecting the exploitation of entrepreneurial opportunities in the field of sports tourism in developing countries such as Iran and the time domain of research, from December 1, 2019 to June 15, 2020. The statistical population of the present 
study includes all managers and officials in the Ministry of Sports and Youth of the Islamic Republic of Iran, managers and officials of sports departments of Iran's provinces, managers and officials of the Cultural Heritage, Tourism and Handicrafts Organization of Iran, professors and experts in sports management, PhD students in sports management, managers and officials of the Federation of Public Sports, managers and officials of leisure and tourism agencies and entrepreneurs and business owners in the field of sports tourism, of which 25 people were considered as purposive sampling as a research sample. Interviewing is the main method of gathering information in this research. In this study, by in-depth and semi-structured interviews, was asked participants to comment on the institutional factors influencing the exploitation of sports tourism entrepreneurship opportunities in developing countries such as Iran. According to Shane and Venkataraman (2000) individual-opportunity nexus framework, interview questions about the regulatory / legal / administrative, normative / cultural, cognitive / educational and guiding / supporting dimensions that affect the use of entrepreneurial opportunities were asked from participants in the study[16]. It should be noted that the participation of individuals in this research was completely optional and people participated in this research with full satisfaction. The number of interviews continued until theoretical saturation. Interviews with individuals were also conducted in person meetings and online through virtual networks. Researchers first interviewed participants in the study in person meetings; but since then, due to the outbreak of the coronavirus and the observance of health protocols, researchers have been able to communicate with people through virtual networks and through various applications, and have conducted the interview process. Interviews ranged from 35 to 70 minutes. In addition, the researchers used existing textbooks, published scientific articles, reviewed various sports and tourism sites, and interviewed experts in the field of tourism and entrepreneurship as additional sources of data collection.

Simultaneously with data collection and interviews, data analysis was performed, as data collection, coding, analysis, and study of existing literature were required to achieve the correct insight that explains the phenomena [50]. Open, axial, and selective coding were used to count the first and second level categories (axes) and their relationships. Categories were based on code refinement, deletion of duplicate codes, comparison and review of embryonic codes with codes previously obtained. In the end, for the validity of the findings, the results were presented to several interviewees in the form of tables and reports to be reviewed and corrected by them; because in a qualitative approach, the results obtained must be understood by the actors themselves and expressed in their own language, and if the actors fail to understand the meaning of the findings, qualitative research will be in vain. The findings were also compared with the results of other researchers and existing theories to confirm its accuracy and validity [51]. To increase the reliability and validity of the research, the following measures were taken: reliability in qualitative research refers to the possibility of conducting research by another independent researcher and achieving similar results from the same data. For this purpose, based on the recommendations provided by qualitative researchers, first of all, all the processes of this research, from preparing the interview protocol to coding, have been documented in detail so that other researchers can follow the process of reaching data from the results. Also, the reliability of the research was increased by using several people in coding and checking the data with the participants. The internal validity of the research also indicates the extent to which the results and interpretations are correct and based on reality and not based on the researcher's mental conjecture. To enhancement the internal validity of the research, several researchers have been used, checking with colleagues, returning to the participants. The most important strategy for increasing external 
credibility is to achieve theoretical saturation in interviews. In this study, by conducting 25 indepth and semi-structured interviews, this was achieved.

\section{Findings}

\section{Demographic information of the participants in the study}

The study involved 25 people from the community for interviews, of which 17 were men and 8 were female. The majority of participants in the study $(60 \%)$ were over 45 years old and $40 \%$ were between 26 and 44 years old. Of these, 12 persons had a doctorate degree, 5 ones had a doctoral degree in sports management, 5 persons had a master's degree, and 3 ones had a bachelor's degree. All interviewees had at least 10 years of scientific and research experience in sports tourism and entrepreneurship in sports tourism.

Following the findings of the study, by using of simultaneous analysis of the coding process, during and after the interviews, the institutional factors affecting the exploitation of entrepreneurial opportunities for sports tourism in Iran were identified through open and axial coding. The open coding of the interviews indicated that the 84 primary indicators could be effective on exploiting entrepreneurial opportunities in Iranian sports tourism, which were ultimately categorized in the final 75 indicators. In the step after the open coding process, the axial coding process took place. During the axial coding process, the researchers used analytical tools to ask questions and make constant and theoretical comparisons between dimensions, sub-dimensions, and features that appeared in open coding to develop relationships between dimensions and sub-dimensions. As a result, the final indicators were classified into 11 pivotal factors, of which 4 final dimensions emerged, which can be seen in Table 1.

Table 1: Extraction of secondary axial codes (dimensions / components) and policy indicators / tools

\section{Dimensions/Components Axial Factors Indicators/Political tools sample}

Develop an effective law for the presence of intermediaries and entrepreneurs in cyberspace

Develop sufficient, necessary and specific rules for sports tourism businesses

Development of laws to protect entrepreneurs in this

Rule of Law $\quad$ field (spiritual support for entrepreneurs)

Creating a safe and legal environment for the public

to enter the sports tourism industry

Homogenization of the rules of the organizations related to sports tourism

Establish stability and transparency in laws

Changing attitudes towards government policies in the field of sports business

Reduce tensions and national and regional political crises and reduce sanctions

Administrative and legal $\quad \begin{gathered}\text { Policies of } \\ \text { Government }\end{gathered}$ dimension
Giving enough authority and freedom to business owners in this area

Eliminate barriers and expedite the process of obtaining employment licenses

Accelerate the implementation of sports tourism development programs 
Increase the executive guarantee of contracts between entrepreneurs and relevant organizations

Identity formation among companies and agencies active in the field of sports tourism

Determining the single trustee and providing the supervised authority to the said institution for legislation in this area

Investigation of sports tourists' complaints according to the country's law

Develop security policies for special sports tourism areas such as beaches

The dynamic growth of the economic environment of the sports tourism industry through the serious reform and revision of banking laws and regulations, such as reducing the requirements and legal steps to provide banking facilities with appropriate bank rates to new and start-up companies.

Eliminate cultural and social restrictions on the promotion of sports tourism

Considering the general welfare of the society Increasing the social and cultural capacities of the sports tourism environment

Social Norms

Increasing citizens' awareness of the benefits of sports tourism

Holding annual national and international gatherings and conferences

Creating a culture and attracting social participation in the development of individual health through participation in recreational and sports spaces

Institutionalizing the culture of sports entertainment among different segments of society

Promoting understanding of opportunities and capabilities in the sports tourism industry to create a proper attitude towards wealth and capital among

Normative / cultural dimension
Values stakeholders, activists and applicants

Encourage top active entrepreneurs and organizations

in the field of sports tourism that are most satisfied with customers

Provide financial incentives and tax exemptions for top entrepreneurs

Introducing the best entrepreneurs and organizations active in the field of sports tourism

Promoting the spirit of hospitality culture of the people of the country

Development of social and cultural capital of sports tourism events and entrepreneurship centers through the establishment of a counseling and training service center 
Promoting the culture of organizational entrepreneurship in sports tourism by creating the appropriate structure and culture of organizations

Promoting economic security for risk appetite and investing in the sports tourism industry to promote a culture of risk aversion in the environment

Promoting entrepreneurial intention and tendency in the sports tourism industry by supporting social and cultural norms of entrepreneurship

Promoting a culture of creativity and ideology in the sports tourism industry by reforming the structure and repressive culture of the country

Culture building through advertising teasers Promoting organizational entrepreneurship in sports tourism centers by creating job incentives Increasing the number of people trained in the country to familiarize people with the benefits of sports tourism

Creating the appropriate scientific and technological

Improving the knowledge of the elite

Cognitive / Educational Dimension support for the development of sports tourism by developing the relationship between the university and the sports tourism industry

Promoting knowledge and technology in the sports tourism industry with higher education in the field of entrepreneurship and sports tourism

Establishment of academic disciplines in the field of sports tourism in universities across the country

Marketing, management and entrepreneurship training for intermediary companies in the field of sports tourism

Learning foreign languages, especially target languages

Provide the opportunity to use the experiences of other countries in the field of entrepreneurship in sports tourism

Providing a scientific environment and sports tourism technology

Promoting social knowledge
Teaching entrepreneurial skills in the family

Training and growth of risk appetite and investment

in the sports tourism industry through mechanisms to reduce uncertainty in the sports tourism market environment

Increasing entrepreneurial intention and orientation in the sports tourism industry through entrepreneurship education in the field of education related to sports science and tourism

Promoting creativity and ideation in the sports tourism industry through training, documenting and disseminating the experiences of tourism entrepreneurs 
Provide the economic infrastructure needed for sports tourism businesses

Supporting the country's banking systems for entrepreneurs in the field of sports tourism

Reduce the cost of purchasing and maintaining equipment and facilities in various sectors of sports tourism

Increasing government investment in sports tourism

Proper use of advertising in the field of sports tourism Efforts by government agencies to introduce sports tourism attractions to tourists

Enhancing sports entrepreneurship processes by using of system management

Promoting legal political support for the sports tourism industry by de-bureaucratizing the organization's structure, strengthening intra-sector links

Government Sector Support

\section{Guiding / Supportive dimension}

\begin{tabular}{|c|c|}
\hline & $\begin{array}{l}\text { tourism and the elimination of the existing } \\
\text { weaknesses in the technical and engineering } \\
\text { management of sports and tourism }\end{array}$ \\
\hline & $\begin{array}{l}\text { Creating intermediary institutions that facilitate } \\
\text { information }\end{array}$ \\
\hline & $\begin{array}{l}\text { Facilities and financial assistance to entrepreneurs in } \\
\text { the field of sports tourism }\end{array}$ \\
\hline & $\begin{array}{l}\text { Review and redesign of entrepreneurial processes in } \\
\text { the sports tourism industry through structural and } \\
\text { program reform }\end{array}$ \\
\hline & $\begin{array}{l}\text { Ability to understand opportunity and capability in } \\
\text { the sports tourism industry through information and } \\
\text { legal support }\end{array}$ \\
\hline Private Sector & $\begin{array}{l}\text { Development of financial resources and capital in the } \\
\text { sports tourism industry through loans, facilities and } \\
\text { credits, formation of an independent investment fund }\end{array}$ \\
\hline & $\begin{array}{c}\text { Develop physical capital and facilities in the sports } \\
\text { tourism industry by increasing private sector } \\
\text { participation and investment }\end{array}$ \\
\hline & $\begin{array}{l}\text { Economic growth and employment in the sports } \\
\text { tourism industry through the support of small and } \\
\text { medium industries }\end{array}$ \\
\hline & Establishment of financial facilitator intermediaries \\
\hline Complementary & $\begin{array}{l}\text { Expansion of biodiversity and environmental health } \\
\text { through the strategy of expanding the geographical } \\
\text { and indigenous context of the regional domain of } \\
\text { entrepreneurship in the tourism industry }\end{array}$ \\
\hline attraction & $\begin{array}{l}\text { Establishment of consulting institutions for starting } \\
\text { businesses in the field of sports tourism }\end{array}$ \\
\hline & Creating physical infrastructure (transportation, etc.) \\
\hline
\end{tabular}

The attention of the trustees to the geographical and indigenous context of the development of sports tourism and the elimination of the existing aknesses in the technical and engineering management of sports and tourism information the field of sports tourism program reform Ability to understand opportunity and capability in legal support

Development of financial resources and capital in the credits, formation of an independent investment fund tourism industry by increasing private sector participation and investment

Economic growth and employment in the sports medium industries

Establishment of financial facilitator intermediaries Expansion of biodiversity and environmental health through the strategy of expanding the geographica and indigenous context of the regional domain of entrepreneurship in the tourism industry businesses in the field of sports tourism 
Promoting welfare services and developing sports infrastructure by strengthening the strategy of developing sports tourism entrepreneurship resources with a diversity approach

Development of human resources and capital in the sports tourism industry through the creation of a stakeholder database

Information

Develop a chain of innovation in sports tourism

Technology products and services through the creation of national and regional information networks

Creating information-based infrastructure Development of sports communications and exchanges through the strategy of restructuring the strategy and management of the development of sports tourism entrepreneurship with a flexible approach

According to Table 1, the following final model can be drawn for the effective institutional factors on the exploitation of Iran's sports tourism entrepreneurship opportunities. 


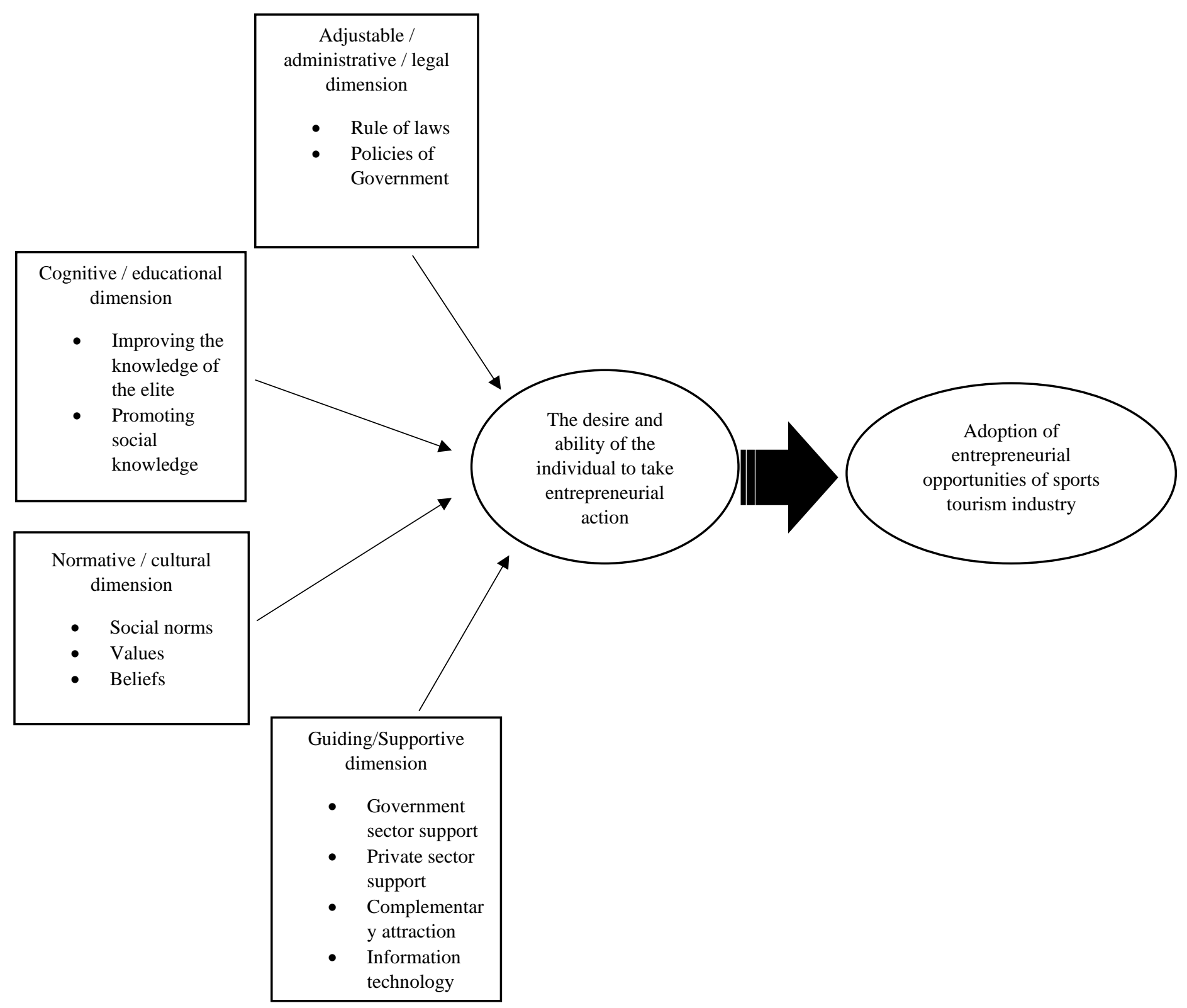

Figure 2: The final research model

\section{Discussion and Conclusion}

According to individual-opportunity nexus framework [16] in exploiting entrepreneurial opportunities, in addition to the role of the individual, context and opportunity are important in creating and improving the quality of entrepreneurial activity. The entrpreneurial environment that helps an entrepreneur realize idea of engaging in entrepreneurial activities are important. Our study identified the institutional factors affecting the adoption of entrepreneurship opportunities in sports tourism using Iran as a context. The legal, normative, supportive and educational environment may have an impact on the desire and ability of market participants to identify and take advantage of sports tourism opportunities in developing countries such as Iran. Our research findings in Table 1 show that the necessary institutional arrangements in the regulatory / legal / administrative (rule 
of law, government policies), normative / cultural (social norms, values and beliefs), cognitive / educational (promotion of elite knowledge, social knowledge promotion and guiding / supportive dimensions (government sector support, private sector support, complementary attraction and information technology) may increase the rate of entrepreneurial behavior in this area by enhancing the desire and ability of entrepreneurs to take advantage of entrepreneurial opportunities in sports tourism.

Administrative and legal dimension is one of the important institutional factors, the role of governments is much more prominent than other factors, for instance having a legal structure for sports tourism, rendering it easier for entrepreneurs to start a business. Our results align with Rodrick et al.'s (2017) study on the role of government in business performance. Our findings however contradict Kaynak \& Kuan (1993) arguing that institutional environment has a limited impact on the performance of tourism businesses in the Philippines[47, 48]. A possible reason for this discrepancy is the different research contexts (Iran and Philippines) and other intervening factors, including entrepreneurial culture and government structure and also Meiling et al (2021) confirmed the effect of social capital on the development of tourism in China in a study that was inconsistent with the present study. Further, there are unstructured businesses in the field of sports tourism that operate without the necessary permits Further, there are unstructured businesses in the field of sports tourism that operate without the necessary permits that Organizing them requires study. Olfateh and Savadi (2016) found that individual and personal factors, time constraints, psychological factors, poor management, lack of awareness and education, social environment, lack of participation and support of others and the activity environment are obstacles to the development of sports tourism in Shiraz Women's Park, respectively They were[52]. These constitute a major barrier to having structured sports jobs in this area. Also, having other co-actors e.g. tourism organizations, the Ministry of Sports and Youth working together with sports businesses and obtaining the necessary licenses to set up and develop sports tourism entrepreneurship is a great obstacle for sports entrepreneurs. Very often, this prevents the individual from pursuing his/her entrepreneurship dream. Amini et al. (2019) in a study found that barriers to sports tourism, components are classified into four sections: management, infrastructure, cultural-political and communication-advertising. Government's policies in this regard should not be neglected[53]. The Ministries of Sports, Youth and Tourism and banking institutions need to provide further support to promote the sports tourism industry. Providing incentives and attractive banking interest rates, developing security policies in tourism settings can contribute to promotion of sports tourism in Iran. Security is very significant, sports entrepreneurs must ensure the security of sports tourists. In particular, foreign tourists are interested in traveling to a place where they feel safe. Eslami et al. (2016) in a study found that in order to develop sports tourism and national use of its revenues, barriers to the entry of tourists must first be removed in advance, and in this regard, the first steps are to provide infrastructure and infrastructure facilities[54].

Our findings show that the normative and cultural dimension of sports tourism entrepreneurship is another important institutional factor to contribute to economic growth and development. Marujo et al. (2020) considered cultural tourism as one of the important branches of tourism that has a close relationship with other areas of tourism[55]. In Nelson's (2019) study, culture is considered as a momentous factor in promoting sustainable tourism with use of bicycles for intercity tourism, this was necessary to create a cycling culture among the people[56]. Increasing awareness among students about entrepreneurship in sports tourism may encourage them to be future entrepreneurs or/and help the spread of sports tourism in society. Municipalities, universities and other non- 
governmental organizations through the strategy of health and culture building in sports recreation, holding annual national and international conferences, increasing citizens' awareness of the benefits of sports tourism, improving the social and cultural capacities of sports tourism environment and most importantly, taking into account the level of public welfare in society may assist in creating a culture of sports tourism which has potential to contribute to the economy. Another consequential point about the norm is to pay attention to the prevailing values and individual values. Different segments of society need to put exercise and physical and recreational activities as one of the important components of health in the family's economic portfolio and consider the cost of sports activities as an investment their children's future.

In the context of our study, promoting sports tourism in developing countries such as Iran may motivate entrepreneurs to join the industry. Entrepreneurs who are influential in the growth of the industry should not be overlooked, further the relevant government agencies need to appreciate the role of tourists as an important stakeholder in the industry. Workshops and seminars can be organised showcasing examples of entrepreneurial success. Further, promoting the culture of organizational entrepreneurship in sports tourism with a focus economic security for risk appetite, promoting entrepreneurial behaviors with the support of social and cultural norms of entrepreneurship and promoting the culture of creativity and ideation in the sports tourism industry need to be considered.

Cognitive and educational factors are another substantial institutional dimension affecting adoption of entrepreneurial opportunities in sports tourism in developing countries such as Iran. The growth of any industry requires full knowledge and training of people [57]. Reese et al. (2020) expressed the transfer of inter-organizational knowledge to tourism as an important factor in the development of the tourism industry[58]. Sports tourism requires the educating the present generations about its contribution to sustainability; universities could consider sports tourism entrepreneurship to be integrated in their curriculum. Furthermore, promoting social knowledge by teaching marketing and entrepreneurship techniques to individuals and intermediaries in the field of sports tourism, teaching foreign languages to applicants for more effective communication with foreign tourists, having the cooperation of science and technology parks to further develop this field and supporting new ideas and using the potential of the media, including television, to broadcast documentaries on sports tourism businesses and interviewing entrepreneurs from around the world can contribute to develop sports tourism in Iran.

The guiding and supportive factors are another dominant institutional dimension that has a much greater impact on the entrepreneurial engagement in sports tourism. We consider the issue of support in two dimensions: (1) government sector support, (2) private sector support. Having the necessary infrastructure is key to show the potential of sports tourism. Kanwal et al. (2020) argue that people's understanding of road infrastructure and transportation is directly related to community support for tourism leading to community satisfaction [59]. Private sector can provide financial support to attract more investors, it is important for the government and private sector to adopt a multi-stakeholder approach which will yield collective.

Sports tourists who travel to participate or assist sports events may need hotels, parking, shopping markets, cultural souvenirs to mention a few, this will require a good tourism planning. Virtual networks can be a notable factor in promoting tourism products to other potential tourists around the world, investment in technology is key.

\section{Conclusion and Recommendations}


Finally, according to the research results, it can be suggested that for the growth of the sports tourism industry in developing countries such as Iran, many factors must be involved in the growth of this industry with more convergence. Governments are the first key to success by supporting entrepreneurs in this area and also providing the necessary financial resources, creating the necessary infrastructure for sports tourism, including transportation, education, promoting sports tourism, foreign policy, and more should be considered by them, so that private sector can be another important lever for the development of the sports tourism industry in Iran by investing and boosting businesses. In the meantime, people can have a big impact. As families teach entrepreneurship to their children, support their children's creative ideas, and the implementation of them, they can grow and prosper as entrepreneurs and can help society by raising creative and entrepreneurial children in the economic, social, and cultural dimensions.

In general, this study provides new insights into the institutional factors affecting the exploitation of entrepreneurial opportunities in the field of sports tourism, and it is hoped that the results of this research will be used by researchers, managers and policymakers. This study also examines the effective institutional factors on the exploitation of entrepreneurial opportunities by surveying experts in this field. Whether or not these institutional factors actually increase the rate of entrepreneurial behavior requires multidisciplinary research projects or comparing different institutional contexts to examine comparisons of these factors that could be an attractive path for future research. Researchers interested in the sports tourism industry are also encouraged to identify other hidden dimensions of the industry and offer further solutions to overcome the barriers to business growth in this field. Reviewing and identifying the factors influencing the attraction of private sector investment in sports tourism is another important research that can reveal many other hidden sides of this industry.

\section{Research limitations}

Every research in its executive path is faced with environmental, temporal, spatial, etc. limitations that can in some cases have direct and indirect effects on the research results. One of the limitations of the present study was that its implementation coincided with the outbreak of coronavirus that due to the special safety conditions against this virus, access to the subjects was much more difficult than normal, which complicated the conditions of the interview with the experts and set the time of the interview with them, which was a reason to increase the time of compiling the article. On the other hand, the emerging industry of the sports tourism in Iran and the hidden sides of the industry in Iran, have made it a little difficult to find researchers who are experts in this field and can achieve acceptable results based on their opinions.

\section{References}

1. Chowdhury, M., et al., Postdisaster social capital, adaptive resilience and business performance of tourism organizations in Christchurch, New Zealand. Journal of Travel Research, 2019. 58(7): p. 1209-1226.

2. Fetscherin, M. and R.-M. Stephano, The medical tourism index: Scale development and validation. Tourism Management, 2016. 52: p. 539-556.

3. Nasr, N.E.S., Risk management in the Light of travel agencies activity in Egypt. International Journal of Heritage, Tourism, and Hospitality, 2017. 10(2/2).

4. Ramzaninejad, R., M.R. Boroumand, and F. Ahmadi, Content analysis of research articles in sport tourism of Iran. Annals of Applied Sport Science, 2020. 8(1): p. 0-0.

5. Pratt, S. and D. Tolkach, The politics of tourism statistics. International Journal of Tourism Research, 2018. 20(3): p. 299-307. 
6. Darbellay, F. and M. Stock, Tourism as complex interdisciplinary research object. Annals of Tourism Research, 2012. 39(1): p. 441-458.

7. Pereira, E., M. Mascarenhas, and G. Pires, SPORT EVENTS'POTENTIATION PROCESS AT PORTIMÃO TOURISM RESORT. Sport Tourism: New Challenges in a Globalized World., 2015: p. 95.

8. Brown, G., A. Smith, and G. Assaker, Revisiting the host city: An empirical examination of sport involvement, place attachment, event satisfaction and spectator intentions at the London Olympics. Tourism management, 2016. 55: p. 160-172.

9. Emery, P., Past, present, future major sport event management practice: The practitioner perspective. Sport management review, 2010. 13(2): p. 158-170.

10. Higham, J. and T. Hinch, Sport and tourism research: A geographic approach. Journal of Sport \& Tourism, 2006. 11(1): p. 31-49.

11. van der Zee, E., Image improvement as a tangible legacy of Hallmark Events; the case of the 2010 World Cup in South Africa. 2011.

12. Lamont, M., Authentication in sports tourism. Annals of Tourism Research, 2014. 45: p. 1-17.

13. Gibson, H.J., K. Kaplanidou, and S.J. Kang, Small-scale event sport tourism: A case study in sustainable tourism. Sport management review, 2012. 15(2): p. 160-170.

14. Darabi, M., et al., Scenario Planning of the Future of Sports Tourism Industry in Mashhad. Annals of Applied Sport Science, 2020. 8(4): p. 0-0.

15. Shane, S., E.A. Locke, and C.J. Collins, Entrepreneurial motivation. Human resource management review, 2003. 13(2): p. 257-279.

16. Shane, S. and S. Venkataraman, The promise of entrepreneurship as a field of research. Academy of management review, 2000. 25(1): p. 217-226.

17. Davidsson, P., The entrepreneurship research challenge. 2009: Edward Elgar Publishing.

18. Sobel, R.S., Testing Baumol: Institutional quality and the productivity of entrepreneurship. Journal of Business Venturing, 2008. 23(6): p. 641-655.

19. North, D.C., Institutions, institutional change and economic performance. 1990: Cambridge university press.

20. Peng, M.W., et al., The institution-based view as a third leg for a strategy tripod. Academy of Management Perspectives, 2009. 23(3): p. 63-81.

21. Sarlab, R., Z. Alipour Nadinlouie, and H. Dehghanpouri, Predictive study of sports tourism development in East Azerbaijan province based on tourism dimensions. Research sponsorship, management and marketing of sports, 2021. 1(4): p. 115-97.

22. Veal, A., Planning for leisure, sport, tourism and the arts: goals and rationales. World Leisure Journal, 2011. 53(2): p. 119-148.

23. Perić, M., V. Vitezić, and J.Đ. Badurina, Business models for active outdoor sport event tourism experiences. Tourism Management Perspectives, 2019. 32: p. 100561.

24. Watanabe, Y., et al., Attracting international spectators to a sport event held in Asia. International Journal of Sports Marketing and Sponsorship, 2018.

25. Hinch, T. and E. Ito, Sustainable sport tourism in Japan. Tourism Planning \& Development, 2018. 15(1): p. 96-101.

26. Deniz, S. and F. Yenel, The Structural Analysis of Physical Education and Sports System in The Turkish Republic of Northern Cyprus. Procedia-Social and Behavioral Sciences, 2013. 89: p. 772780.

27. Hodeck, A., D. Eckert-Lindhammer, and L.C.F. dos Santos. Expectation and perceived experience of Rio 2016: The perspective of Latin American Stakeholders. in 9th INTERNATIONAL SPORT BUSINESS SYMPOSIUM. 2018.

28. Hua, K.P., I. Ibrahim, and L.K. Chiu, Sport tourism: Physically-disabled sport tourists'orientation. Procedia-Social and Behavioral Sciences, 2013. 91: p. 257-269.

29. Nová, J., Developing the entrepreneurial competencies of sport management students. ProcediaSocial and behavioral sciences, 2015. 174: p. 3916-3924. 
30. Ball, S., The importance of entrepreneurship to hospitality, leisure, sport and tourism. Hospitality, leisure, sport and tourism network, 2005. 1(1): p. 1-14.

31. Ratten, V., The Future for Sport Entrepreneurship, in Sport Entrepreneurship. 2018, Springer. p. 139-149.

32. Booth, P., et al., Entrepreneurship in island contexts: A systematic review of the tourism and hospitality literature. International Journal of Hospitality Management, 2020. 85: p. 102438.

33. Jaafar, M. and S.M. Rasoolimanesh, Tourism growth and entrepreneurship: Empirical analysis of development of rural highlands. Tourism management perspectives, 2015. 14: p. 17-24.

34. Shane, S., Reflections on the 2010 AMR decade award: Delivering on the promise of entrepreneurship as a field of research. Academy of Management Review, 2012. 37(1): p. 10-20.

35. Zhang, S.-N., et al., Critical factors identification and prediction of tourism and hospitality students' entrepreneurial intention. Journal of Hospitality, Leisure, Sport \& Tourism Education, 2020. 26: p. 100234.

36. Fong, V.H.I., I.A. Wong, and J.F.L. Hong, Developing institutional logics in the tourism industry through coopetition. Tourism Management, 2018. 66: p. 244-262.

37. Zahra, S.A., Contextualizing theory building in entrepreneurship research. Journal of Business venturing, 2007. 22(3): p. 443-452.

38. Peng, M.W., Global business. 2016: Cengage learning.

39. Eunni, R.V., Institutional environments for entrepreneurship in emerging economies: Brazil Vs. Mexico. World Journal of Management, 2010. 2(1): p. 1-18.

40. Henseler, J., C.M. Ringle, and R.R. Sinkovics, The use of partial least squares path modeling in international marketing, in New challenges to international marketing. 2009, Emerald Group Publishing Limited.

41. Nawaz, S., Growth effects of institutions: A disaggregated analysis. Economic Modelling, 2015. 45: p. 118-126.

42. Scott, W.R., Institutions and organizations. Foundations for organizational science. 1995, London: A Sage Publication Series.

43. Stenholm, P., Z.J. Acs, and R. Wuebker, Exploring country-level institutional arrangements on the rate and type of entrepreneurial activity. Journal of Business Venturing, 2013. 28(1): p. 176-193.

44. Veciana, J.M. and D. Urbano, The institutional approach to entrepreneurship research. Introduction. 2008, Springer.

45. Glaeser, E.L., et al., Do institutions cause growth? Journal of economic Growth, 2004. 9(3): p. 271303.

46. Perera, L.D.H. and G.H. Lee, Have economic growth and institutional quality contributed to poverty and inequality reduction in Asia? Journal of Asian Economics, 2013. 27: p. 71-86.

47. Kaynak, E. and W.K.-y. Kuan, Environment, strategy, structure, and performance in the context of export activity: an empirical study of Taiwanese manufacturing firms. Journal of Business Research, 1993. 27(1): p. 33-49.

48. Rodrik, D., A. Subramanian, and F. Trebbi, Institutions rule: the primacy of institutions over geography and integration in economic development. Journal of economic growth, 2004. 9(2): p. 131-165.

49. Matteucci, X. and J. Gnoth, Elaborating on grounded theory in tourism research. Annals of Tourism Research, 2017. 65: p. 49-59.

50. Glaser, B.G., Doing Quantitative Grounded Theory. 2008: Sociology Press.

51. Creswell, J.W. and C.N. Poth, Qualitative inquiry and research design: Choosing among five approaches. 2016: Sage publications.

52. Olfateh, M. and M. Savadi, Identify and prioritize the barriers of sports tourism in urban public spaces. Geography (Regional Planning), 2016. 6(4): p. 83-97.

53. Amini, A., Z. Khosh Sepehr, and Z. Yousefi, Identifying the Promoting and Restricting Factors of Development of Sport Tourism in the Public Sector (Case of Study: Ministry of Sport and Youth). Journal of Iranian Public Administration Studies, 2019. 2(2): p. 69-90. 
54. ESLAMI, S., J. HEMMATI, and E. ZARRINI, An Investigation about the Barriers to Sport Tourists to Inter Iran. 2016.

55. Marujo, N., M. do Rosário Borges, and J. Serra, Tourism, culture and creativity: the case of the CREATOUR project in the Alentejo/Portugal region, in Advances in Tourism, Technology and Smart Systems. 2020, Springer. p. 691-704.

56. Nilsson, J.H., Urban bicycle tourism: Path dependencies and innovation in Greater Copenhagen. Journal of Sustainable Tourism, 2019. 27(11): p. 1648-1662.

57. Brandão, F., et al., Knowledge creation and transfer in tourism innovation networks, in Advances in Tourism, Technology and Smart Systems. 2020, Springer. p. 275-287.

58. Raisi, H., et al., A network perspective of knowledge transfer in tourism. Annals of Tourism Research, 2020. 80: p. 102817.

59. Kanwal, S., et al., Road and transport infrastructure development and community support for tourism: The role of perceived benefits, and community satisfaction. Tourism Management, 2020. 77: p. 104014. 